\title{
An investigation of renal function in chronic bronchitis
}

\author{
Peter Daggett \\ M.B., M.R.C.P.
}

Department of Medicine, Brompton Hospital, Fulham Road, London SW3

\begin{abstract}
Summary
An investigation has been made into various parameters of renal function in patients with chronic bronchitis and in a group of hypoxic controls. Abnornalities of glomerular filtration rate and of water handling have been demonstrated in chronic bronchitic patients but not in hypoxic controls. The abnormalities are related to the arterial $\mathrm{PCO}_{2}$. A hypothesis is presented as to the role of $\mathrm{CO}_{2}$ in causing abnormalities of renal function in chronic bronchitis.
\end{abstract}

\section{Introduction}

In the syndrome of cor pulmonale secondary to chronic bronchitis, patients are hypoxic and often suffer from fluid retention. In addition, they have a respiratory acidosis which may be only partially compensated for by renal mechanisms. Thus the kidney is an important organ in determining the clinical picture. A study has been instituted of some parameters of renal function in long-standing chronic bronchitis, and an attempt has been made to correlate these with arterial blood gas tensions.

\section{Methods}

Informed consent was obtained from the bronchitic patients and a group of hypoxic controls. The bronchitic patients conformed to the MRC criteria and were known to have had an arterial $\mathrm{PCO}_{2}$ of at least $55 \mathrm{~mm}$ for more than 1 year. They were studied in their stable condition, when they were not in acute exacerbation. The control patients were known to have an arterial $\mathrm{Po}_{2}$ of less than $45 \mathrm{~mm}$ and a normal $\mathrm{PCO}_{2}$ in the range $36-46 \mathrm{~mm}$. These conditions were known to have been present for at least 1 year. Patients who were taking diuretics had their drugs stopped $48 \mathrm{hr}$ before commencing the test programme (Gibson, Marshall and Lockey, 1970). The protocol is given in Table 1 .

\section{Ethylenediamine tetraacetate (EDTA) clearance (Chantler et al., 1969)}

This measurement approximates closely to the glomerular filtration rate (GFR). An intravenous

Present address: Department of Medicine, Middlesex Hospital, Mortimer Street, London WIN 8AA.
TABLE 1. Protocol of investigations

\begin{tabular}{|c|c|}
\hline Day 1 & $\begin{array}{l}\text { Blood gas estimation. } \\
\text { EDTA clearance. } \\
\text { Urea and electrolyte estimation. } \\
\text { Plasma protein estimation. } \\
\text { Full blood count. }\end{array}$ \\
\hline Day 2 & Fluid deprivation test. \\
\hline Day 3 & Water load test. \\
\hline Day 4 & Urinary acidification test. \\
\hline Day 5 & Tetracosactide stimulation test (if required). \\
\hline
\end{tabular}

injection was given at time zero, of $100 \mu \mathrm{Ci}$ of ${ }^{51} \mathrm{Cr}$ labelled EDTA. Blood samples were taken 2, 3, 3.5 and $4 \mathrm{hr}$ after the injection, collection being into heparinized tubes. A well counter was used to measure the activity of the specimens, and from these the clearance was established.

\section{Arterial blood gases}

A direct reading electrode method was used to measure $\mathrm{pH}, \mathrm{PCO}_{2}$ and $\mathrm{PO}_{2}$.

\section{Fluid deprivation test (Hamburger, 1968).}

The patients took a standard dry diet for 12 $\mathrm{hr}$ beforehand and were allowed 1 litre of fluid in the preceding $24 \mathrm{hr}$. A urine specimen was taken at $20.00 \mathrm{hr}$ and all fluids were then withheld overnight until $3 \%$ of the original body-weight had been lost. The first urine passed after this point was discarded, fluid restriction was continued, and the next urine passed was collected as the post-dehydration specimen. Urinary osmolality was measured using a depression of freezing point apparatus (Advanced Instruments).

Water load test (Gibson, Marshall and Lockey, 1970)

This was performed in the morning with the patient fasting. The overnight urine was discarded, and the next urine passed was collected as the zero time sample. An oral water load of $20 \mathrm{ml} / \mathrm{kg}$ bodyweight was then taken over $15 \mathrm{~min}$. Urine was collected at hourly intervals for $6 \mathrm{hr}$ and stored at $4^{\circ} \mathrm{C}$. Osmolality was measured as described above. 
Urinary acidification test (Wrong and Davies, 1959. The short method was used)

The test was carried out in the morning with the patient fasting. The overnight urine was discarded and the next urine passed was taken as the zero time sample. An acid load of $0.1 \mathrm{~g} / \mathrm{kg}$ body-weight ammonium chloride was taken, in $75 \mathrm{ml}$ of flavoured liquid. Urine samples were then taken hourly for $6 \mathrm{hr}$. Urinary $\mathrm{pH}$ was measured on freshly voided urine, using a glass electrode apparatus.

\section{Vasopressin response test}

No special preparations were made. An intramuscular injection of 5 i.u. aqueous vasopressin was given at time zero. Urine samples were collected for the measurement of osmolality, before the injection and 2, 4 and $6 \mathrm{hr}$ thereafter.

\section{Tetracosactide stimulation test}

This was performed on those patients not taking steroids in order to determine that they had an adequate corticosteroid reserve to handle a water load normally.

\section{Results}

There were five patients in each group. In every case, the plasma urea was less than $45 \mathrm{mg} / 100 \mathrm{ml}$, the plasma potassium was in the range 3.5-4.9 $\mathrm{mmol} / \mathrm{l}$ and the plasma sodium was in the range 136-146 $\mathrm{mmol} / \mathrm{l}$. Other relevant data are listed in Table 2.

\section{EDTA clearance}

The laboratory lower limit of normal for the method used was $80 \mathrm{ml} / \mathrm{min}$. There was a linear inverse correlation between arterial $\mathrm{PCO}_{2}$ and the
EDTA clearance, shown in Fig. 1. There was no correlation between clearance and any of the other parameters measured.

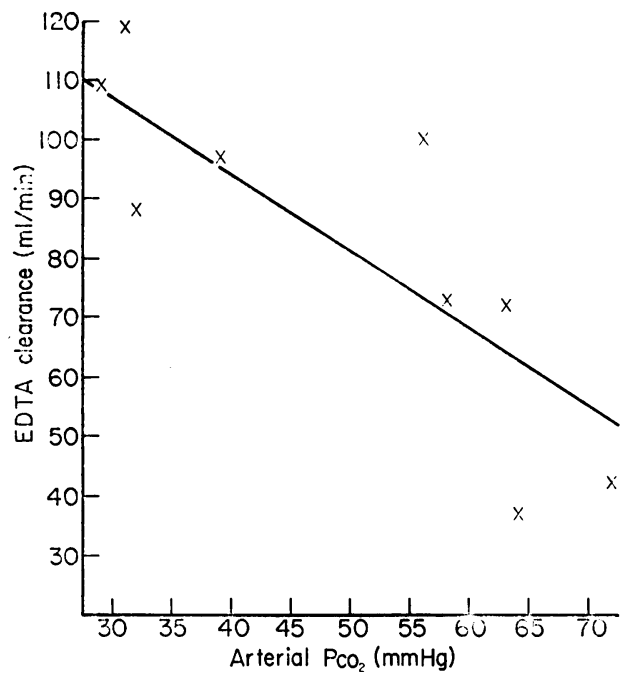

FIG. 1. Correlation between EDTA clearance and arterial $\mathrm{PCO}_{2} r=0.83, P<0.01$.

\section{Concentration and dilution tests}

In the fluid deprivation test, there was no difference between the two groups in their ability to form a concentrated urine. During the water load test, the minimum osmolality was recorded in the urine sample obtained $2 \mathrm{hr}$ after the water load. The ability to dilute the urine was significantly less for the hypercapnic patients when compared with the hypoxic group (Mann and Whitney ' $U$ ' test).

TABLE 2.

\begin{tabular}{|c|c|c|c|c|c|c|c|c|c|}
\hline Case & Diagnosis & Sex & $\begin{array}{c}\text { Age } \\
\text { (years) }\end{array}$ & Steroids & Diuretic & $\begin{array}{c}\text { EDTA } \\
\text { Clearance }\end{array}$ & $\mathrm{pH}$ & $\mathrm{Po}_{2}$ & $\mathrm{PCO}_{2}$ \\
\hline \multicolumn{10}{|c|}{ (a) Hypoxic patients } \\
\hline 1 & Alveolar proteinosis & $\mathbf{F}$ & 22 & Yes & No & 119 & $7 \cdot 41$ & 36 & 31 \\
\hline 2 & $\begin{array}{l}\text { Pulmonary fibrosis } \\
\text { (Untreated allergic } \\
\text { aspergillosis) }\end{array}$ & $\mathrm{F}$ & 52 & Yes & No & 97 & $7 \cdot 47$ & 40 & 39 \\
\hline 3 & Fibrosing alveolitis & $\mathbf{M}$ & 50 & Yes & No & 109 & $7 \cdot 50$ & 45 & 29 \\
\hline 4 & $\begin{array}{l}\text { Pulmonary fibrosis } \\
\text { (Unknown aetiology) }\end{array}$ & $\mathbf{M}$ & 60 & No & Yes & - & $7 \cdot 36$ & 42 & 36 \\
\hline 5 & Fibrosing alveolitis & $\mathbf{M}$ & 61 & Yes & Yes & 88 & $7 \cdot 40$ & 44 & 32 \\
\hline \multicolumn{10}{|c|}{ (b) Hypercapnic patients } \\
\hline 6 & Chronic bronchitis & $\mathbf{M}$ & 64 & No & Yes & 42 & $7 \cdot 35$ & 58 & 72 \\
\hline 7 & Chronic bronchitis & $\mathbf{M}$ & 70 & Yes & Yes & 37 & $7 \cdot 42$ & 33 & 64 \\
\hline 8 & Chronic bronchitis & $\mathbf{M}$ & 62 & Yes & No & 100 & $7 \cdot 38$ & 49 & 56 \\
\hline 9 & Chronic bronchitis & $\mathbf{M}$ & 56 & No & Yes & 72 & $7 \cdot 38$ & 42 & 63 \\
\hline 10 & Chronic bronchitis & $\mathbf{M}$ & 70 & Yes & Yes & 73 & $7 \cdot 40$ & 35 & 58 \\
\hline
\end{tabular}

$\mathrm{Po}_{2}$ and $\mathrm{PCO}_{2}$ are expressed in $\mathrm{mmHg}$; EDTA clearance is expressed in $\mathrm{ml} / \mathrm{min}$. 


\section{Urinary acidification test}

The normal response was taken to be a fall in the urinary $\mathrm{pH}$ to 5.3 or less, within $6 \mathrm{hr}$ of the acid load (Wrong and Davies, 1959). All patients achieved plasma bicarbonate levels during the test at which acid urine might be expected. There was no difference between the two groups, either in the minimum $\mathrm{pH}$ recorded or in the time after the acid load at which minimum $\mathrm{pH}$ was achieved.

\section{Tetracosactide stimulation test}

A normal response was taken to be a rise in plasma cortisol of $15 \mu \mathrm{g} / \mathrm{ml}$ over the basal level. This response was achieved in all the patients in whom the test was carried out.

TABLE 3. Results of concentration and dilution tests

\begin{tabular}{rccr}
\hline Case no. & Group & $\begin{array}{c}\text { Maximum } \\
\text { osmoles }\end{array}$ & $\begin{array}{r}\text { Initial } \\
\text { osmoles }\end{array}$ \\
\hline 1 & H & 1000 & 600 \\
8 & CB & 919 & 554 \\
3 & H & 782 & 555 \\
9 & CB & 771 & 502 \\
5 & H & 748 & 524 \\
6 & CB & 724 & 465 \\
4 & H & 683 & 567 \\
10 & CB & 664 & 541 \\
2 & H & 623 & 565 \\
7 & CB & 608 & 500 \\
\hline & & Minimum & Initial \\
Case no. & Group & osmoles & osmoles \\
\hline 9 & CB & 725 & 502 \\
6 & CB & 705 & 465 \\
8 & CB & 633 & 554 \\
10 & CB & 523 & 541 \\
7 & CB & 483 & 500 \\
1 & H & 286 & 600 \\
5 & H & 147 & 524 \\
4 & H & 142 & 567 \\
3 & H & 134 & 555 \\
2 & H & 100 & 565 \\
\hline
\end{tabular}

Osmoles, urine osmolalities in mosmol/kg; $\mathrm{H}$, purely hypoxic patients; $\mathrm{CB}$, patients with chronic bronchitis.

\section{Vasopressin response test}

All patients responded to exogenous vasopressin, with a rise in urinary osmolality to greater than 800 mosmol $/ \mathrm{kg}$ within $6 \mathrm{hr}$ of the injection. This response was rather less than expected in all patients, and it is speculated that the batch of vasopressin employed had reduced potency for some reason.

\section{Discussion}

This study has demonstrated that two of the measured parameters of renal function are abnormal in patients with chronic bronchitis and the abnormality cannot be related to hypoxia. Hypercapnia correlates well with GFR (as measured by EDTA clearance), in addition, hypercapnic patients are unable to dilute their urine during an acute load. An abnormality of GFR has been demonstrated by Platts, Hammond and Stuart-Harris (1960) and by White and Woodings (1971) who were unable to correlate the reduction with the degree of hypercapnia. It is known that in chronic bronchitis the filtration fraction is reduced (Fishman et al., 1951) and therefore any reduction in GFR is likely to be caused by a reduction in renal plasma flow. If this were dependent upon peripheral pooling consequent upon $\mathrm{CO}_{2}$ related vasodilatation, then GFR could vary inversely with the arterial $\mathrm{PCO}_{2}$. This phenomenon is illustrated by the present study which would seem to support the hypothesis.

The ability to dilute the urine on acute loading correlates with the ability to excrete a water load. An abnormality in water handling has been observed in chronic bronchitis (White and Woodings, 1971) and related to the arterial $\mathbf{P C O}_{2}$. A similar relationship has been observed in the present study, but this did not correlate with the GFR. There is possibly a tubular abnormality which results in inappropriate retention of sodium and water. This would be important in the pathogenesis of the fluid retention of cor pulmonale.

Campbell has discussed the interrelationship between renal handling of sodium and of hydrogen ion (Campbell and Short, 1960). He raised the possibility that the kidney excretes an excess of $\mathrm{H}^{+}$

TABLE 4. Results of urinary acidification tests

\begin{tabular}{rccccccc}
\hline Case & $2 \mathrm{hr} \mathrm{HCO}_{3}{ }^{*}$ & Initial $\mathrm{pH}$ & One hour & Two hour & Three hour & Four hour & Five hour \\
\hline 1 & 20 & $6 \cdot 7$ & $5 \cdot 6$ & $5 \cdot 9$ & $5 \cdot 9$ & $6 \cdot 0$ & -1 \\
2 & 19 & $6 \cdot 8$ & $6 \cdot 0$ & $4 \cdot 9$ & $4 \cdot 5$ & $4 \cdot 7$ & $5 \cdot 9$ \\
3 & 18 & $6 \cdot 8$ & $6 \cdot 0$ & $5 \cdot 3$ & $5 \cdot 0$ & $4 \cdot 9$ & $5 \cdot 4$ \\
4 & 18 & $6 \cdot 6$ & $6 \cdot 0$ & $4 \cdot 8$ & $4 \cdot 8$ & $5 \cdot 2$ & $5 \cdot 4$ \\
5 & 19 & $6 \cdot 6$ & $6 \cdot 5$ & $5 \cdot 7$ & $4 \cdot 3$ & $5 \cdot 3$ & $5 \cdot 4$ \\
6 & 21 & $4 \cdot 8$ & $4 \cdot 7$ & $4 \cdot 4$ & $4 \cdot 3$ & $5 \cdot 4$ & $-7 \cdot 3$ \\
7 & 22 & $6 \cdot 7$ & $6 \cdot 9$ & $6 \cdot 5$ & $6 \cdot 6$ & $6 \cdot 3$ & $6 \cdot 3$ \\
8 & 19 & $6 \cdot 0$ & $5 \cdot 5$ & $5 \cdot 4$ & $5 \cdot 3$ & $4 \cdot 7$ & $5 \cdot 0$ \\
9 & 18 & $5 \cdot 3$ & $4 \cdot 8$ & $4 \cdot 5$ & $4 \cdot 3$ & $4 \cdot 8$ & $5 \cdot 1$ \\
10 & 19 & $5 \cdot 6$ & $4 \cdot 9$ & $4 \cdot 6$ & $4 \cdot 4$ & $4 \cdot 3$ & $5 \cdot 6$ \\
\hline
\end{tabular}

* This refers to the plasma bicarbonate concentration (in mmol/1), $2 \mathrm{hr}$ after the acid load. 
because the lungs do not dispose of sufficient $\mathrm{CO}_{2}$. The increased $\mathrm{H}^{+}$loss might result in a concomitant retention of sodium ions. The present study has demonstrated no abnormality of acid handling as judged by simple $\mathrm{pH}$ measurement. Further investigation with measurement of titratable acidity and of ammonium excretion may provide evidence in support of Campbell's hypothesis.

The kidney occupies an important role in the pathogenesis of the clinical syndrome of cor pulmonale. The abnormalities noted in this preliminary study appear to be related to arterial $\mathbf{P c O}_{2}$. Further study may enable a group of renal risk factors to be produced which might predict those patients liable to develop cor pulmonale.

\section{Acknowledgments}

I should like to thank the physicians of the Brompton Hospital who allowed me to study their patients, particularly Professor M. Turner-Warwick, Dr T. Clark and Dr H. Nicholson.

\section{References}

CAMPBell, E.J.M. \& SHORT, D.S. (1960) The cause of oedema in cor pulmonale. Lancet, i, 1184.

Chantler, C., Garnett, E.S., Parsons, V. \& Veall, N. (1969) Glomerular filtration rate in man by the single injection method using Cr-EDTA. Clinical Science, 37, 160.

Fishman, A.P., Maxwell, M.H., Crowder, C.H. \& Morales, P. (1951) Circulation, 3, 703.

Gibson, D.G., Marshall, J.C. \& Lockey, E. (1970) Assessment of proximal tubular sodium reabsorption during water dit resis in patients with heart disease. British Heart Journal, 32, 399.

Hamburger, J. (1968) Nephrology. Saunders, London.

PlatTs, M.M., Hammond, J.D.S. \& Stuart-Harris, C.H. (1960) A study of cor pulmonale in patients with chronic bronchitis. Quarterly Journal of Medicine, 29, 559.

White, R.J. \& Woodings, D.F. (1971) Impaired water handling in chronic obstructive airways disease. British Medical Journal, 2, 561.

Wrong, O. \& Davies, H.E.F. (1959) The excretion of acid in renal disease. Quarterly Journal of Medicine, 28, 259. 